\title{
Study and Analysis of Routing Protocols in V2I Communication using WiMAX on VANET
}

\author{
S.M. Bhagat \\ Research scholar, SGB University, Amravati \\ Department of Information Technology \\ MIT Academy of Engineering \\ Pune, India
}

\author{
Vijay M. Wadhai \\ Principal \\ Singhgad Academy of Engineering \\ Pune, India
}

\begin{abstract}
Vehicular Ad-hoc Network (VANET) is a network of vehicles (wireless mobile nodes) which is formed when vehicles came in to range. In VANET, topology is not fixed, it changes periodically. Since there is a change in the topology due to high speed of vehicles, unpredictable behavior of driver, hidden node problems, VANET becomes the interesting domain for the researchers to provide safety to general public on road.

The paper throw light on study and analysis of routing protocols like AODV, DYMO in V2I for various parameters like packet delivery ratio, throughput, end to end delay, Data packet loss and Energy consumption. Simulation for highway scenario was performed for 12 vehicles and 4 base stations with variable velocity in QualNet Simulator and WiMAX (8012.16) was used for the VANET infrastructure.
\end{abstract}

\section{Keywords}

VANET, WiMAX, Data Packet Loss, base station, Energy consumption, 802.16

\section{INTRODUCTION}

VANET is extension to mobile ad-hoc network (MANET), VANET can be classified as infrastructure less and infrastructure based. The only difference between VANET and MANET is that mobile nodes are vehicles with high mobility than nodes in MANET. Due to different speeds of vehicles on road and ad-hoc nature of network, they cannot remain in contact for longer period of time in network. Thus there is need of infrastructure to bring nodes in contact for longer period of time to exchange the compunction through infrastructure which is installed along the road side as base or fixed station. VANET have following characteristics like High Speed of nodes, Dynamic topology, unpredictable behavior of driver, energy constrained, hidden node problems, uneven distribution of vehicles on road. [4]

This paper aims to simulate, implement and analyze the existing protocol in Infrastructure based VANET in order to observe the performance in terms of metrics like packet delivery ratio, Data Packet loss, throughput, end to end delay using QualNet simulator to provide safety on road[5]

Literature review carried out for Ad hoc on demand distance vector (AODV) and Dynamic MANET on Demand (DYMO) routing protocols with the following point

It was found at the time of review that routing protocols are the important aspect in the performances of VANET. It is also found that the major problem in infrastructure less VANET is communication range. Due to this, there is frequently disconnection of network. It is also noted that efficiency of routing protocol is not up to the mark. It is also observed that protocol was designed to maximize network life time as well.
The performance metrics is used to measure the efficiency is PDR, throughput, versus bitrate and density considering network layer

\section{ROUTING PROTOCOLS}

Because of high speed of vehicles on road and formation of network in dynamic nature, maintaining route information throughout is major problem which is one of the hottest point for the researchers. There are many result put forward in same context that can be divide in to mainly proactive, reactive, position based and hybrid. AODV and DYMO are from reactive category where route is discovered only when source node has data to send to destination node. Mainly two control packets RREQ and RREP are used for route discovery. RREQ packet is initiated by source $\&$ it is forwarded to destination node through neighbor nodes. Upon receiving RREQ packet, the destination node sends RREP packets to reserve the path to the source. Finally data packets are delivered to the destination. [3, 7, 8]

\section{QUALNET SIMULATOR FOR EXPERIMENTAL SETUP}

QualNet simulator was used for this research work. It is cost effective method for developing and deployment of routing protocol in VANET. IT allows to analyze the performance of routing protocol in terms of parameter like packet delivery ratio, throughput, Jitter by varying the value line, no of nodes, packet size, changing bit rate, changing infrastructure, and so on.[6]

\section{SIMULATION ENVIRONMENT}

Infrastructure based VANET is created using WiMAX with four base stations to cover highway and 6 vehicles are used at either side of highway with variable velocity with simulation area $1500 \mathrm{mx} 1500 \mathrm{~m}$, simulation time was $900 \mathrm{~s}$ with four wireless channel of type two ray with following networking details other parameters are summarized in the table 1

Initially Vehicles (mobile nodes) 5, 13 are connected to base station 1 is part of wireless subnet 1 . Similarly other vehicles are part of wireless subnet 2 to 4 . Start time for delivering packet is set to $100 \mathrm{~s}$ to get mobility in the vehicles. [5] the infrastructure was WiMAX with mac protocol 802.16 and physical radio 802.16 for improving the network connectivity as well as network coverage. [1,

Table 1. Simulation Parameter

\begin{tabular}{|c|c|c|}
\hline Sr.No & parameter & specification \\
\hline 01 & velocity & variable \\
\hline 02 & MAC protocol & 802.16 \\
\hline 03 & Physical Radio & 802.16 \\
\hline 04 & Battery model & Linear \\
\hline
\end{tabular}




\begin{tabular}{|c|c|c|}
\hline 05 & Wireless channel & Two Ray \\
\hline 06 & Traffic type & CBR \\
\hline 07 & Packet Size & 512 \\
\hline 08 & Interval between packet & fixed \\
\hline 09 & Simulation area & $1500 \mathrm{~m} \times 1500 \mathrm{~m}$ \\
\hline 10 & Simulation time & $15 \mathrm{~min}$ \\
\hline 11 & Initial battery & mAhr \\
\hline 12 & Routing Protocols & AODV,DYMO \\
\hline 13 & Source and destination & fixed \\
\hline 14 & Start time to send packet & $100 \mathrm{~s}$ \\
\hline 15 & Antenna height & $1.5 \mathrm{~m}$ \\
\hline
\end{tabular}

\section{RESULTS AND DISCUSSION}

The following parameters are used for comparative analysis of AODV and DYMO routing protocol using WiMAX on VANET considering highway scenario. The performance of below mentioned parameters is analyzed at Application, Network and Physical Layer.

1. Packet Delivery ratio: It is the ratio of total no of packet received at node to total no of packet sent by all nodes

2. Throughput: number of bits received successfully per second. Which implies the quality of routing protocol

3. End to end delay: The difference between end time and start time to send packet.

4. Jitter: It is the variation in latency which is measured in accordance to the variability over time of the packet latency across the same network.

5. Data Packet Loss: it is difference between the data packet sent as source and Data packet received at destination node.

6. Energy consumed: The total energy utilized by the vehicles on roads which is measured in terms of MJoules.

7. Battery capacity: It is measured in terms of mAhr

Based on above metrics experiment is carried out.

\subsection{Discussion and analysis between AODV and DYMO}

Result obtained from QualNet simulator for the parameters evaluated at Application Layer are placed on graph as shown in the figure $1,2,3,4$. The packet delivery ratio and throughput in DYMO is better as compared to AODV routing protocol. According to the analysis for the highway scenario the packet delivery ratio is $51 \%$ and throughput is $13161 \mathrm{bits} / \mathrm{sec}$ in DYMO. Whereas AODV is better than DYMO with respect to End to end delay and jitter. The corresponding values are $0.29 \mathrm{~s}$ and $0.22 \mathrm{~s}$ in AODV.

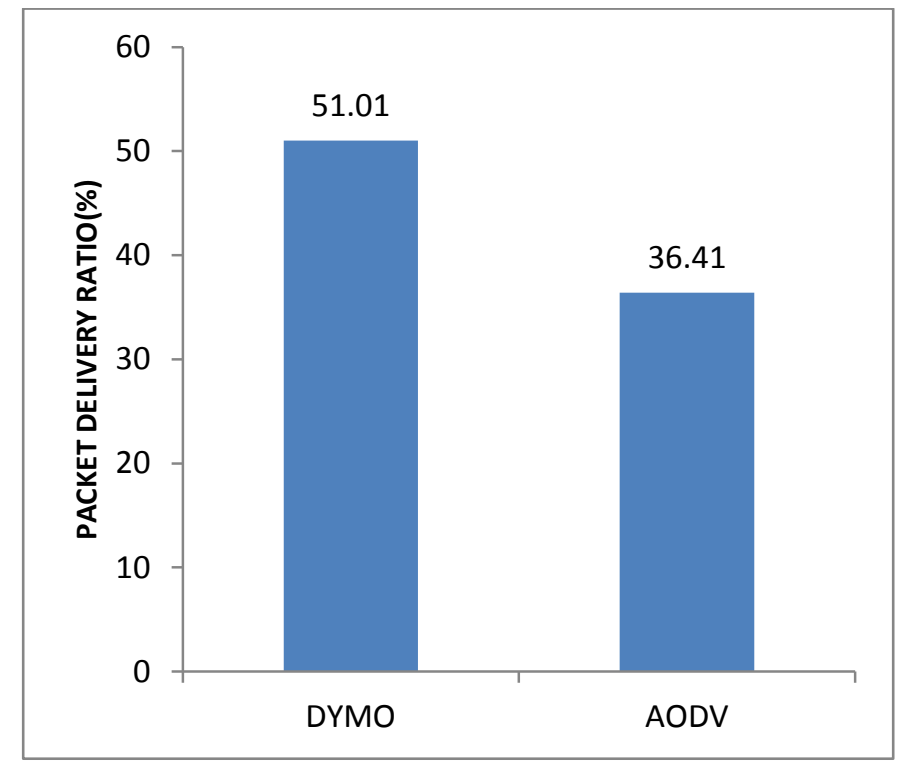

Fig 1:Packet delivery ratio(\%) at node 1 and node 4

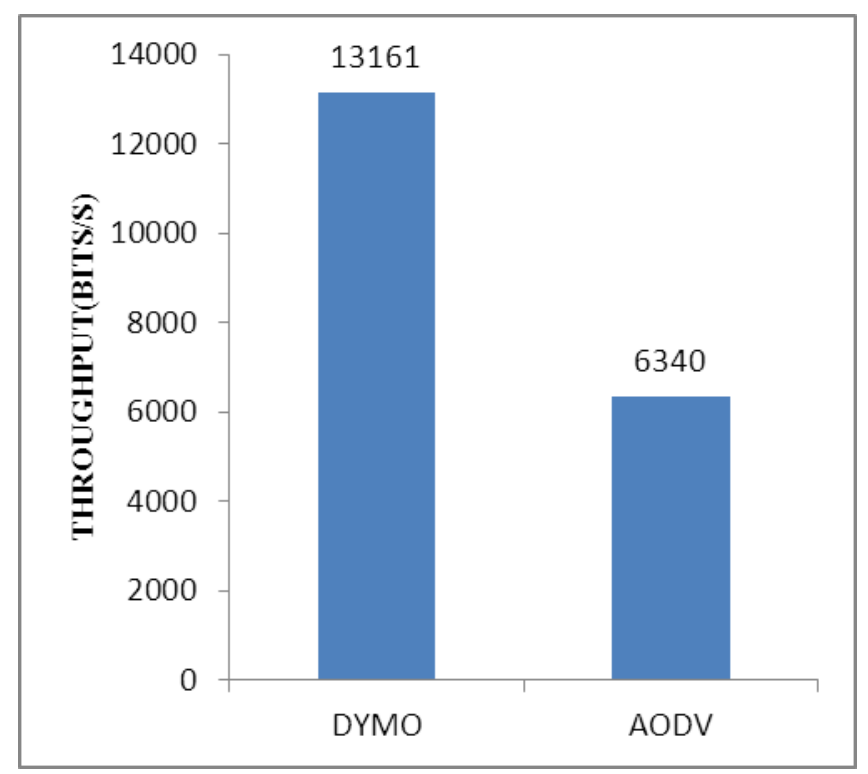

Fig 2: Throughput ( bits/s) at node 1 and node 4 


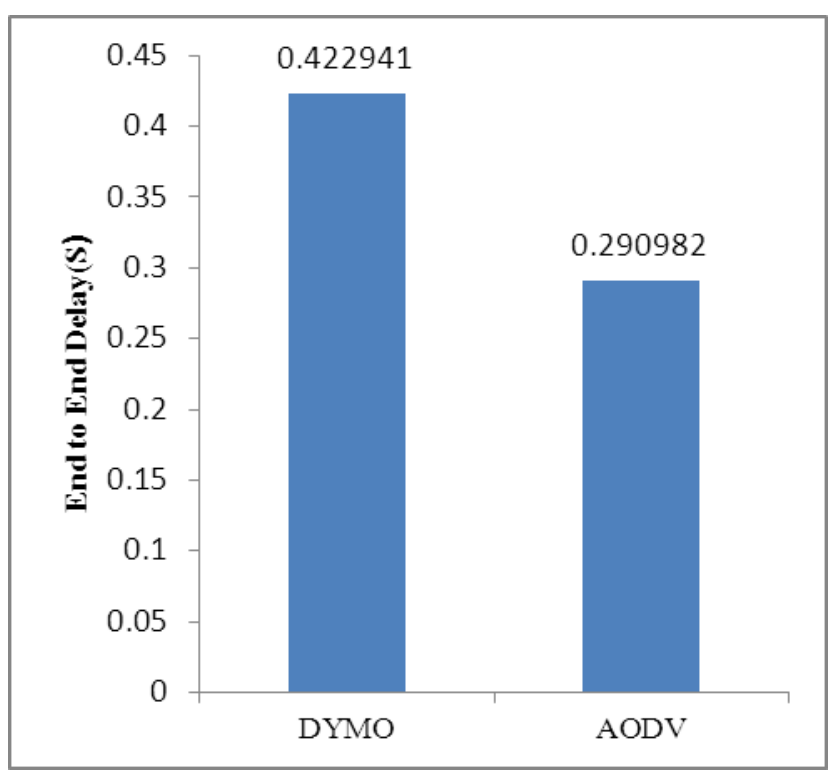

Fig 3: End to End delay

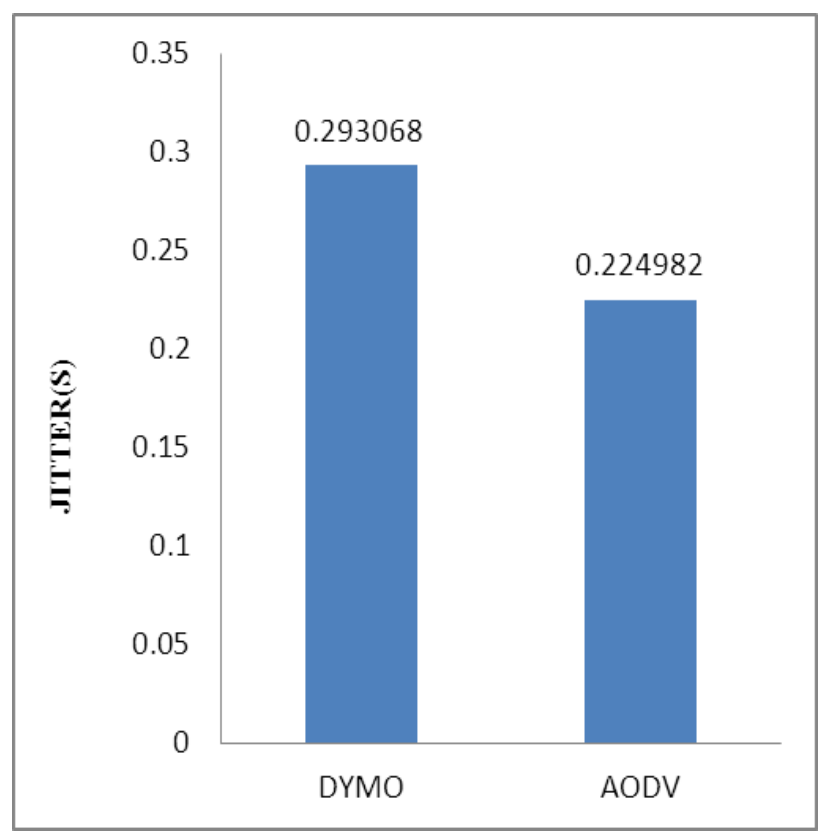

Fig 4:Jitter at node 1 and node 4

The following set of graphs discusses data packets send, data packets received and data packet lost at network Layer. As per the analysis done in figures 5,6,7 DYMO is fast in Data delivery. The data packets send are much higher than AODV but the data packet loss is very less as compared to DYMO.

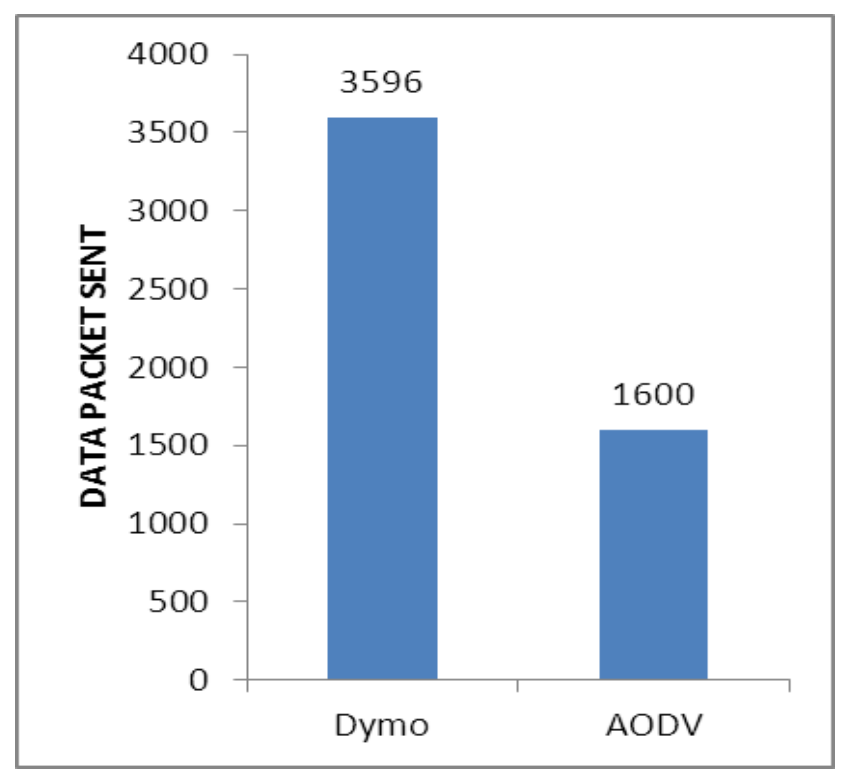

Fig 5: Data Packet sent as source Nodes

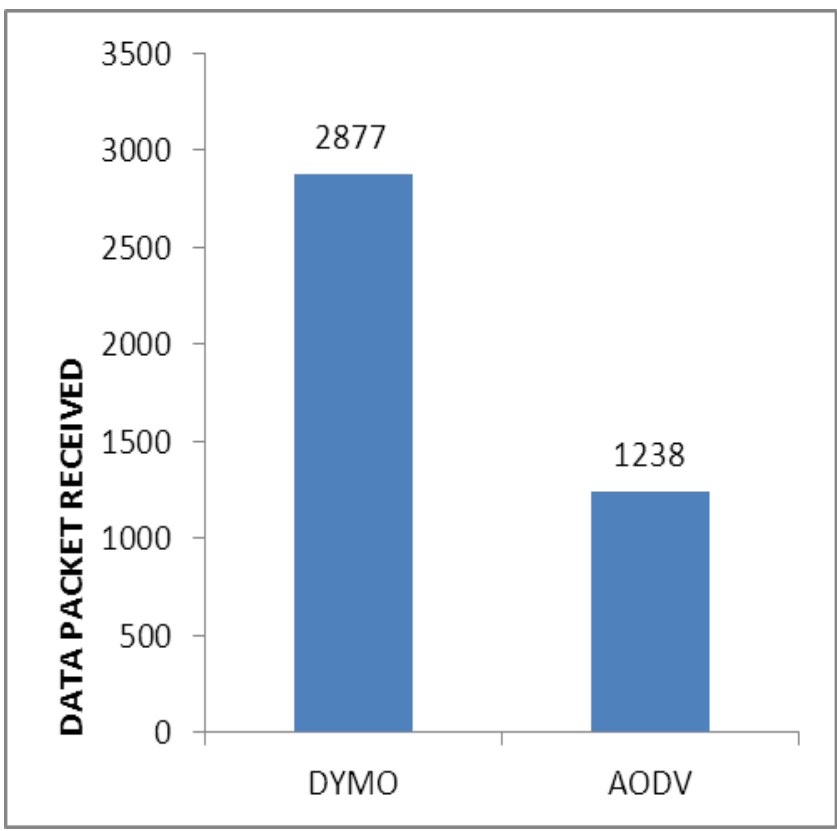

Fig 6: Data Packets received as source Nodes

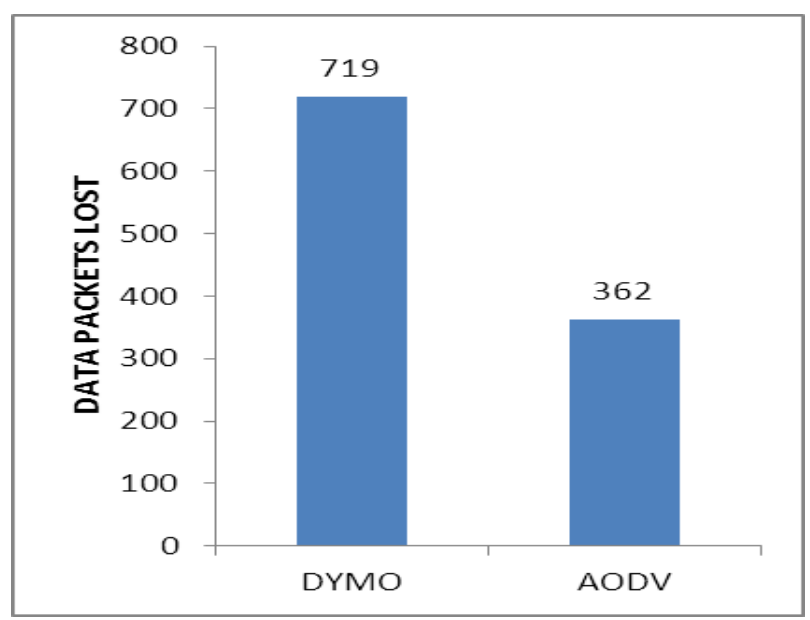

Fig 7 : Data Packets lost at node 1 and node 4 
The next set of graph shows the performance of DYMO and AODV with respect to energy consumed in transmit mode and battery utilization at Physical layer. The analysis in figure 8,9 states that the energy consumption is more in DYMO due to higher packet delivery rate. The battery utilization in both the protocols is almost the same.

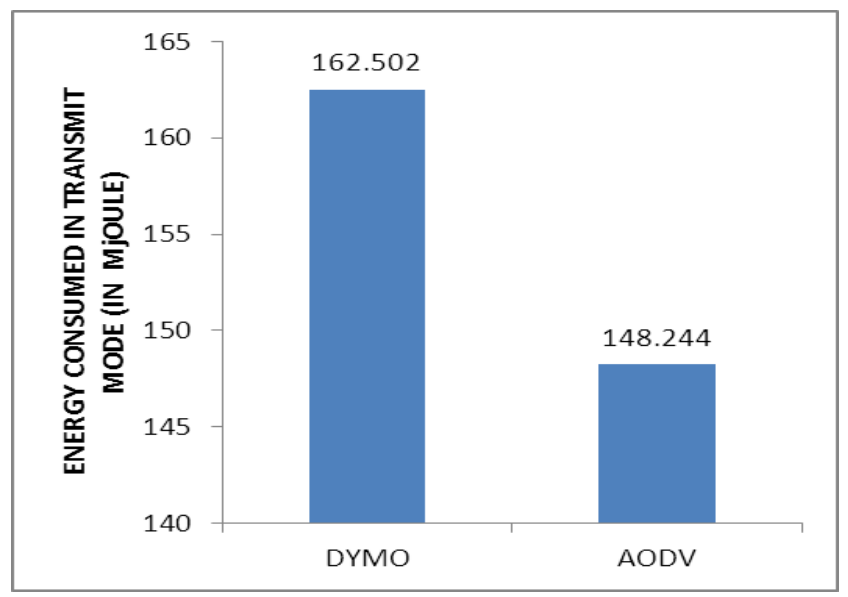

Fig 8: Energy consumed in transmit mode

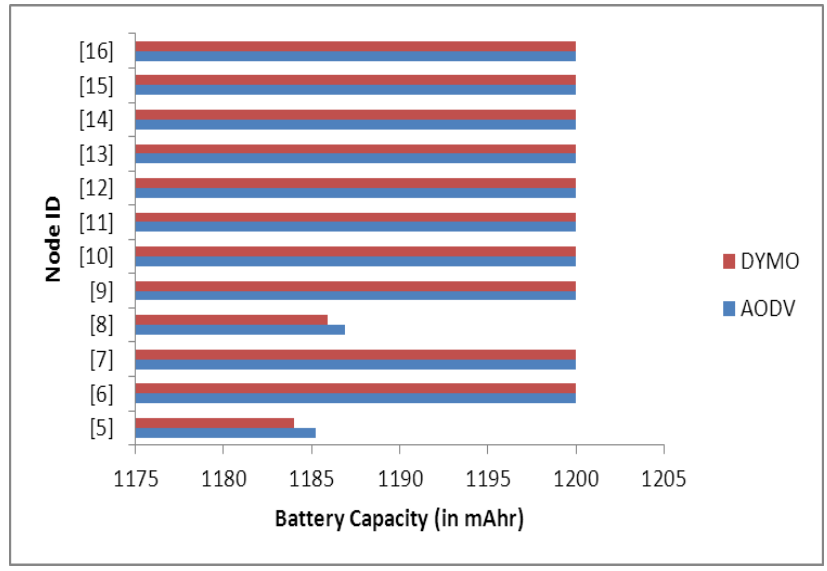

Fig 9: Battery Capacity (in mAhr )for mobile nodes)

\section{CONCLUSION}

The highway scenario was designed considering four lanes using Wi-MAX infrastructure for low density with fixed bit rate and the variable velocity of the vehicle. Performance of AODV and DYMO routing protocols are evaluated with respect to packet delivery ratio, throughput, end to end delay and data packet loss. From the result obtained through QualNet simulator, it is concluded that DYMO is far better routing protocol than AODV in terms of parameters mentioned above but in Network Layer performance of DYMO deteriorates in terms of data packet loss as compared to AODV.

Future work of this activity is to examine the performance of DYMO and AODV with variable bit rate and variable network load in highway scenario in WiMAX on VANET.

\section{ACKNOWLEDGEMENT}

We take this opportunity to thank Dr. V. M. Thakare, Head Research Center, and Amravati University for their valuable guidance and for providing all the necessary facilities

\section{REFERENCES}

[1] Muhmad Rizwan Arshad, Shahid Mehmood, salaman Afar "An Evaluation of study of WiMAX and WiFi on Vehicular Ad-Hoc Networks (VANETs)", International Journal of scientific Engineering and Research Volume 3 Issue 12 , December -2012

[2] Takano, A.,Niigata Univ., Niigata,Okada, H. ; Mase, K.” Performance Comparison of a Position-Based Routing Protocol for VANET" .IEEE Internatonal Conference on Mobile Adhoc and Sensor Systems, 2007. MASS 2007

[3] Kabiwa, M.S. , Djouani, K. ; Kurien, A. "Performance comparison of IBETX routing metric over AODV and DSDV routing protocols "Wireless Communications and Mobile Computing Conference (IWCMC), 2014 International

[4] Chen, T. Mehani, O. ; Boreli, R." Trusted routing for VANET" 9th International Conference on Intelligent Transport Systems Telecommunications,(ITST),2009

[5] Prof. Bhagat Sunilkumar Madhusudan, Prof (Dr.) Wadhai V.M" Study Of The Effect Of Velocity On End-Toend Delay For V2v Communication In ITS" International Journal of Next-Generation Networks (IJNGN) Vol.4, No.4, December 2012

[6] The QualNet Simulator http://web.scalablenetworks.com/content/QualNet

[7] Zulklfli M. Yusof and J. A. Flint "Performance Metrics for the path prediction of link and path avialabilty in VANETS" proceeding of 2009 IEEE conference

[8] Christoph sommer and Falko Dressler "The DYMO Routing Protocol in VANET scenarios "proceeding of 2007IEEE conference 